\title{
Identifying Significant Antipsychotic-Related Side Effects in Patients on a Community Psychiatric Rehabilitation Unit-A Feasibility Study of The Glasgow Antipsychotic Side-Effect Scale (GASS)
}

\author{
Ahmed Saeed Yahya* \\ Camden Islington NHS trust, UK \\ *Corresponding author: Ahmed Saeed Yahya, Matthew Allin BA Research Centre, Camden Islington NHS trust, London, United Kingdom \\ Submission: 温 May 07, 2018; Published: 海 November 01, 2018
}

\begin{abstract}
Antipsychotic side-effects are common and are an important determinant of non-adherence and consequent relapse. Most rating scales for the identification of these are lengthy and complicated. This report reviews the medical literature on the Glasgow antipsychotic side-effect scale (GASS)-a brief and validated rating scale to measure the unwanted effects of antipsychotics. We administered the GASS to fourteen in-patients in a United Kingdombased Community Psychiatric Rehabilitation Unit. The objective was to establish the utility of the GASS in this setting and to make recommendations on how this tool could be used in clinical practice to improve adherence to antipsychotic medication.
\end{abstract}

Keywords: GASS; Psychiatric; Community rehabilitation; Anti psychotics

\section{Introduction}

Antipsychotic side-effects are common and disabling. They are an important determinant of non-adherence and consequent relapse Robinson et al. [1]. The CATIE study in 2005, which enrolled 1500 patients with Chronic Schizophrenia, showed a high rate of treatment discontinuation (up to $74 \%$ ) during the 18 month period of the trial. The median time to discontinuation of treatment was 6 months Nystazaki et al. [2]. Most rating scales for the identification of antipsychotic side-effects are either dependent on clinical assessment (and therefore labour intensive) or are lengthy and detailed. Therefore, they are often not completed or completed incorrectly. Side effect scales can be differentiated on generalisation and structure i.e. if they are measuring specific clusters of symptoms or a range of these. Some of the rating scales are designed to assess for specific side effects from antipsychotic medication. Examples of these scales include; the Barnes Akathisia Scale which evaluates akathisia (feeling of inner restlessness and inability to stay still). The Abnormal Involuntary Movement Scale (AIMS) assesses for tardive dyskinesia. The Simpson Angus rating Scale (SAS) assesses for symptoms of Parkinsonism. More generalised screening measures include the Liverpool University Neuroleptic Side Effect Rating Scale (LUNSERS) which consists of 51 questions. Some of the items include 'red herring' questions' which can be useful for identifying patients who are over rating their side effects Haddad et al. [3]. Scales can be differentiated further on the basis that they are patient or clinician completed.
The Glasgow Antipsychotic Side-effect Scale (GASS; Waddell \& Taylor [4] was designed as a brief, but valid self-completion scale. It is one of the most practical and straightforward for routine clinical use (can be completed before outpatient appointment). It takes five minutes to complete and contains self-explanatory questions in simple English. It is a structured tool to measure the important antipsychotic side effects, and there is a column on the scale to measure the subjective level of distress/functional impairment caused by the specific adverse effect. In this report, we summarise the findings of a pilot evaluation of the GASS in a cohort of patients on a Community Psychiatric rehabilitation unit.

\section{Methods}

The GASS is a 22-item scale of possible side-effects, with symptoms rated as present 'never', 'once', 'a few times' and 'every day' during the previous week for the first 20 symptoms, and the other two (change in periods [women only] and weight gain) rated over the past 3 months and as either present or absent. The scale has a possible score range between 0 and 63 . The questionnaire form used was identical to that in the Waddell \& Taylor [4] paper. The GASS was administered on a single occasion to 14 in patients in our Community Rehabilitation Unit. Since the study was a quality improvement project and the data collected were routine patient data, consent was obtained verbally and there was no need for ethical approval to be sought. The GASS provides sub-scores on 9 domains 
of possible side effects: sedation and central nervous system; cardiovascular; extrapyramidal; anticholinergic; gastro-intestinal; Genito-urinary; diabetes-indication; hyperprolactinaemia indicators and weight gain.

\section{Results}

Thirteen out of a total of 14 patients agreed to complete the study. Of the 13 who completed the form, all but one filled the form in its entirety. One patient left out the score for one item (weight gain) 7 were female and 6 were male. Their age ranged between 32 and 65 years (Mean 42.9). All 13 patients who completed the form had a diagnosis of a Treatment Refractory Psychosis. Nine of these patients were taking Clozapine as an Anti- Psychotic medication. The GASS total scores ranged between 1 and 57. Five patients had GASS scores in the 'Severe' range, four had 'Moderate' side-effects and four reported only having 'Mild' side-effects (Table 1). The most frequent side effects experienced were in the Central Nervous System and diabetes risk indicator domains. Genito-urinary symptoms and hyperprolactinaemia indicators were relatively infrequent as were anticholinergic symptoms (Table 2).

Table 1: GASS score summary.

\begin{tabular}{|c|c|c|c|c|c|c|c|c|c|c|c|c|c|c|c|c|c|c|}
\hline $\begin{array}{l}\text { Pa- } \\
\text { tient } \\
\text { num- } \\
\text { ber }\end{array}$ & $\begin{array}{c}\text { Gen- } \\
\text { der }\end{array}$ & Age & $\begin{array}{l}\text { To- } \\
\text { tal }\end{array}$ & $\begin{array}{c}\text { Catego- } \\
\text { ry } \\
\text { Mild/ } \\
\text { mod/ } \\
\text { severe }\end{array}$ & $\begin{array}{c}\text { CNS } \\
\text { Total } \\
\text { 01- } \\
\text { Feb }\end{array}$ & $\begin{array}{c}\text { CNS } \\
\text { Mean } \\
(2)\end{array}$ & $\begin{array}{l}\text { CVS } \\
\text { To- } \\
\text { tal } \\
\text { 03- } \\
\text { Apr }\end{array}$ & $\begin{array}{l}\text { CVS } \\
\text { Mean- } \\
2\end{array}$ & $\begin{array}{c}\text { EPS } \\
\text { Total } \\
\text { 05-0ct }\end{array}$ & $\begin{array}{c}\text { EPS } \\
\text { Mean- } \\
6\end{array}$ & $\begin{array}{c}\text { Anti- } \\
\text { chol } \\
\text { Total } \\
\text { Nov- } \\
13\end{array}$ & $\begin{array}{c}\text { Anti- } \\
\text { chol } \\
\text { Mean } \\
-3\end{array}$ & $\begin{array}{l}\text { GI } \\
14\end{array}$ & $\begin{array}{l}\text { GU } \\
15\end{array}$ & $\begin{array}{c}\text { Dia- } \\
\text { be- } \\
\text { tes } \\
16\end{array}$ & $\begin{array}{c}\text { Pro- } \\
\text { lactin } \\
\text { Tot } \\
\\
17- \\
20 / 21\end{array}$ & $\begin{array}{c}\text { Pro- } \\
\text { lactin } \\
\text { Mean- } \\
3\end{array}$ & $\begin{array}{l}\text { Weight } \\
\text { Gain } 22\end{array}$ \\
\hline 1 & M & 54 & 43 & Severe & 6 & 3 & 5 & 2.5 & 12 & 2 & 2 & 0.67 & 2 & 2 & 3 & 8 & 2.67 & 3 \\
\hline 2 & M & 38 & 3 & Mild & 2 & 1 & 0 & 0 & 0 & 0 & 0 & 0 & 0 & 0 & 0 & 0 & 0 & 0 \\
\hline 3 & $\mathrm{~F}$ & 41 & 13 & $\begin{array}{c}\text { Moder- } \\
\text { ate }\end{array}$ & 2 & 1 & 0 & 0 & 3 & 0.5 & 0 & 0 & 0 & 0 & 2 & 0 & 0 & 3 \\
\hline 4 & $\mathrm{~F}$ & 65 & 36 & Severe & 6 & 3 & 1 & 0.5 & 14 & 2.33 & 8 & 2.67 & 3 & 0 & 3 & 0 & 0 & 0 \\
\hline 5 & $\mathrm{~F}$ & 43 & 57 & Severe & 6 & 3 & 6 & 3 & 18 & 3 & 9 & 3 & 3 & 0 & 3 & 9 & 2.25 & 3 \\
\hline 6 & M & 37 & 23 & $\begin{array}{c}\text { Moder- } \\
\text { ate }\end{array}$ & 5 & 2.5 & 5 & 2.5 & 5 & 0.83 & 3 & 1 & 0 & 0 & 2 & 0 & 0 & 3 \\
\hline 7 & M & 35 & 31 & Severe & 5 & 2.5 & 2 & 1 & 8 & 1.33 & 2 & 0.67 & 3 & 0 & 3 & 2 & 0.67 & 3 \\
\hline 8 & $\mathrm{~F}$ & 34 & 25 & $\begin{array}{l}\text { Moder- } \\
\text { ate }\end{array}$ & 3 & 1.5 & 3 & 1.5 & 12 & 2 & 2 & 0.67 & 2 & 0 & 3 & 3 & 0.75 & 3 \\
\hline 9 & $\mathrm{~F}$ & 52 & 37 & Severe & 5 & 2.5 & 5 & 2.5 & 16 & 2.67 & 5 & 1.67 & 0 & 1 & 2 & 3 & 0.75 & MV \\
\hline 10 & M & 32 & 1 & Mild & 1 & 0.5 & 0 & 0 & 0 & 0 & 0 & 0 & 0 & 0 & 0 & 0 & 0 & 0 \\
\hline 11 & M & 43 & 5 & Mild & 1 & 0.5 & 0 & 0 & 4 & 0.67 & 0 & 0 & 0 & 0 & 0 & 0 & 0 & 0 \\
\hline 12 & $\mathrm{~F}$ & 40 & 16 & $\begin{array}{c}\text { Moder- } \\
\text { ate }\end{array}$ & 3 & 1.5 & 2 & 1 & 5 & 0.83 & 2 & 0.67 & 1 & 0 & 1 & 0 & 0 & 0 \\
\hline 13 & $\mathrm{~F}$ & 44 & 12 & Mild & 3 & 1.5 & 0 & 0 & 6 & 1 & 0 & 0 & 0 & 0 & 3 & 0 & 0 & 0 \\
\hline
\end{tabular}

Table 2: Range and mean scores per domain.

\begin{tabular}{|c|c|c|}
\hline & Mean Score & Range \\
\hline CNS & 2.54 & $0.5-3$ \\
\hline CVS & 1.12 & $0-3$ \\
\hline EPS & 1.32 & $0-3$ \\
\hline Anticholinergic & 0.85 & $0-3$ \\
\hline GI & 1.08 & $0-3$ \\
\hline GU & 0.23 & $0-2$ \\
\hline Hyperprolactinaemia indicator & 1.92 & $0-3$ \\
\hline Weight gain & 0.55 & $0-2.67$ \\
\hline
\end{tabular}

CNS: Central Nervous System; CVS: Cardiovascular; EPS: Extrapyramidal; Antichol: Anticholinergic; GI: Gastrointestinal; GU: Genito-Urinary; MV: Missing Value

\section{Discussion}

The response rate in this pilot study was high (only 1 person declined out of 14) and almost all participants completed the GASS form it its entirety. The scale only took about 5 minutes for each participant to complete and the scoring and summarizing process was also straight forward. A much higher proportion of participants (69\%) reported significant (moderate or severe) side-effects than the out-patients in the original Waddell \& Taylor [4] paper (24\%). This is unsurprising in view of the severity and chronicity of mental illness in our cohort reflected by their need for a psychiatric rehabilitation care pathway. In keeping with this, 9/13 (69\%) of our participants were prescribed more than one psychotropic. In the Waddell \& Taylor [4] outpatient cohort, only $28 \%$ were on more than one psychotropic. The fact that diabetes risk indicators were frequently reported is significant, given the high prevalence of diabetes among service users with psychosis. Relatively low scores for hyperprolactinaemia indicators are consistent with 
more frequent use of prolactin-sparing (second generation) antipsychotics-particularly clozapine-in this patient group. We conclude that the GASS is a satisfactory instrument for identifying significant antipsychotic side-effects in a rehabilitation unit setting.

\section{Limitations}

GASS does not collect information about constipation-a common unwanted effect of the antipsychotic clozapine, which is commonly used in treatment refractory psychosis. Our results may therefore represent an under-estimate of the true range and prevalence of antipsychotic side effects in this patient group.

\section{Recommendations}

We recommend that patients in long term rehabilitation units should complete the GASS every 3 months, and that total GASS scores within the moderate/severe range should trigger a medication review. Collaborative practice with service users will aid future medication adherence and thus have the potential to make a significant contribution to relapse prevention Cleary et al. [5]. Training in the use of GASS should be made available to clinicians in the Multi-Disciplinary Team (including nurses, OTs, support workers and medical staff) - particularly in teams who care for patients who have treatment-refractory psychosis. We thought it would be helpful to put the item scores $(0,1,2,3)$ onto the GASS scoring sheets to facilitate score totalling. Future research should focus on how the scale can be utilised as a clinical tool to improve real-world outcomes Hynes et al. [6].

\section{Acknowledgement}

We thank the Whittington Health Library, at Whittington NHS Trust for their support with Literature searching. We are also grateful for the administrative support received from the Audit and Medical Records departments at Camden \& Islington NHS Trust.

\section{References}

1. Robinson DG, Woerner MG, Alvir JM, Hinrichsen GA, Lieberman JA, et al. (2002) Predictors of medication discontinuation by patients with first-episode schizophrenia and schizo-affective disorder. Schizophrenia Research 57(2-3): 209-219.

2. Nystazaki M, Tsapakis EM, Hadjulis M, Alevizopoulos G (2014) Validation of the glasgow antipsychotic side-effect scale (GASS) in Greece. Journal of Psychology \& Clinical Psychiatry 1(4): 1-6.

3. Haddad P, Fleischhacker WW, Moller HJ (2014) SMARTS (Systematic monitoring of Adverse events Related to treatments): The development of a pragmatic patient-completed checklist to antipsychotic drug side effects. Therapeutic Advances in Psychopharmacology 4(1): 15-21.

4. Waddell L, Taylor M (2008) A new self-rating scale for detecting atypical or second-generation antipsychotic side-effects. Journal of Psychopharmacology 22(3): 238-243.

5. Cleary A, Walsh F, Connolly H, Hays V, Dowling M, et al. (2012) Monitoring and documentation of side effects from depot antipsychotic medication: an interdisciplinary audit of practice in a regional mental health service. Journal of Psychiatric and Mental Health Nursing 19(5): 395-401.

6. Hynes C, Keating D, Williams S, Madigan K, Clarke M, et al. (2015) Glasgow antipsychotic side-effects scale for clozapine-development and validation of a clozapine-specific side-effects scale. Schizophrenia Research 168(1-2): 505-513.
Creative Commons Attribution 4.0 International License

For possible submissions Click Here

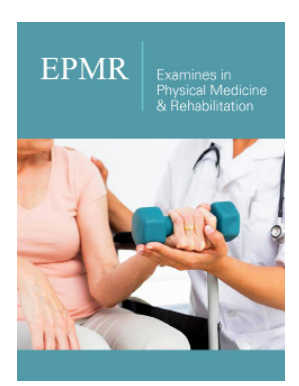

Examines in Physical Medicine and Rehabilitation: Open Access

\section{Benefits of Publishing with us}

- High-level peer review and editorial services

- Freely accessible online immediately upon publication

- Authors retain the copyright to their work

- Licensing it under a Creative Commons license

- Visibility through different online platforms 